\title{
Bob Dylan's ‘A Hard Rain's a-Gonna Fall': Análisis estructural y estilístico de una ruptura poética en el estándar del folk tradicional norteamericano
}

\author{
Jesús Albarrán
}

Recibido: 26.06.2019 - Aceptado: 21.07.2019

\section{Titre / Title / Titolo}

Bob Dylan's 'A hard rain's a-gonna fall': Analyse structurelle et stylistique d'une rupture poétique selon les standards du folk traditionnel nord-américain

Bob Dylan's 'A hard rain's a-gonna fall': Structural and stylistic analysis of a poetic break according to the standards of traditional North American folk music

Bob Dylan's 'A hard rain's a-gonna fall': Analisi strutturale e stilistica di una rottura poetica secondo gli standard del folk tradizionale nordamericano

\section{Resumen / Résumé / Abstract / Riassunto}

Este artículo pretende subrayar el contexto social y creativo donde se gesta la ruptura estética que supuso la canción $A$ Hard Rain's aGonna Fall, compuesta por el cantautor estadounidense Bob Dylan, así como aplicar un análisis estructural y estilístico a los elementos poéticos del himno, concediendo especial atención a sus referencias literarias, musicales y expresivas. La canción protesta norteamericana de principios de los años sesenta presentaba una serie de características realistas que asumirá e integrará Bob Dylan en sus inicios, pero que comenzarán a diluirse progresivamente desde el temprano avance de su carrera musical.

Cet article vise à mettre en lumière le contexte social et créatif dans lequel est née la rupture esthétique de la chanson «A Hard Rain's a-Gonna Fall», composée par l'auteur-compositeur-interprète américain Bob Dylan, ainsi qu’à appliquer une analyse structurelle et stylistique aux éléments poétiques de l'hymne, en portant une attention particulière à ses références littéraires, musicales et expressive. La chanson de protestation américaine du début des années soixante présentait une série de caractéristiques réalistes que Bob Dylan assumera et intégrera dans ses débuts, mais qui commenceront à se dissoudre progressivement à partir du début de sa carrière musicale.
This article aims to highlight the social and creative context in which the aesthetic rupture of the song 'A Hard Rain's a-Gonna Fall', composed by American singer-songwriter Bob Dylan, was born, as well as to apply a structural and stylistic analysis to the poetic elements of the anthem, by paying special attention to its literary, musical and expressive references. The American protest song of the early sixties presented a series of realistic characteristics that Bob Dylan will assume and integrate in his beginnings, but which will begin to dissolve progressively with the early advancement of his musical career.

Questo articolo si propone di evidenziare il contesto sociale e creativo in cui è nata la rottura estetica della canzone "A Hard Rain's a-Gonna Fall”, composta dal cantautore americano Bob Dylan, nonché di applicare un'analisi strutturale e stilistica agli elementi poetici dell'inno, prestando particolare attenzione ai suoi riferimenti letterari, musicali ed espressivi. La canzone di protesta americana dei primi anni Sessanta presentava una serie di caratteristiche realistiche che Bob Dylan assumerà e integrerà nei suoi inizi, ma che cominceranno a dissolversi progressivamente a partire dai primi passi della sua carriera musicale.

\section{Palabras clave / Mots-clé I}

\section{Key words / Parole chiave}

Dylan, folk revival, poesía, simbolismo, generación beat, A Hard Rain's a-Gonna Fall.

Bob Dylan, folk revival, poésie, symbolisme, beat generation,

"A Hard Rain's a-Gonna Fall".

Bob Dylan, folk revival, poetry, symbolism, beat generation,

'A Hard Rain's a-Gonna Fall'.

Bob Dylan, folk revival, poesia, simbolismo, beat generation,

"A Hard Rain's a-Gonna Fall". 


\section{Contexto social y creativo: La crisis de los misiles de Cuba y la revista Broadside}

En otoño de 1962, la histeria social ante una verdadera hecatombe nuclear alcanzó el clímax con la crisis de los misiles de Cuba en octubre. La neurosis generalizada y cotidiana que Dylan atrapó en meses anteriores con la balada I Will No Go Down Under the Ground - posteriormente $I$ Will Die on My Footsteps-, se veía eclipsada ahora por la posibilidad real de una muerte prematura y abominable. Este contexto apocalíptico de tensión social e incertidumbre, bañado por noches de música y vino en el Greenwich Village, el barrio más bohemio de New York, fue la atmósfera donde se acunaría uno de sus éxitos más evocadores: A Hard Rain's a-GonnaFall.

A principios de los años sesenta, una corriente crítica e inconformista con el stablishment recorría las universidades norteamericanas. La política de becas del estado llevaba años posibilitando a cantidades de jóvenes acceder a estudios superiores y la ideología pseudocomunista veía en Cuba y Rusia una alternativa real al capitalismo: Marx y Engels se encontraban entre las lecturas clandestinas de las aulas y el aparente anarquismo y la desinhibición de la poética beat parecía acomodarse estéticamente a este espíritu ávido de libertad y justicia moral que se diluiría años más tarde en la «nueva bohemia» del concepto Hippie. En New York, durante el periodo de composición de $A$ Hard Rain, Dylan se encontraba inmerso en una vorágine creativa impulsada, por un lado, por aquella evocadora, autodestructiva y romántica relación a distancia (Italia, Perugia) con su pareja sentimental: Suze Rotolo; y, por otro, por el empuje creativo de los jóvenes cantautores protesta cercano al Movimiento por los Derechos Civiles que había alentado, desde febrero de ese mismo año, las páginas recién nacidas de Broadside Magazine, la que llegaría a culminar como la revista mimeografiada más reconocida del Segundo Folk Revival — publicada por los músicos Agnes «Sis» Cunninghan y Gordon Friesen-. «Sis» y Gordon, como editores responsables, abrían su casa todas las se- manas: «las oficinas de Broadside», donde jóvenes músicos como Spoelstra, Turner, Tom Paxton, Len Chandler o Phil Ochs se veían estimulados a compartir material, grabar sus temas en cintas de bobina abierta y tocar sus nuevas canciones frente a críticos musicales y literarios tan ilustres y formados en el folk como Cunninghan \& Friesen. La casa de Cunninghan se convertía en el feliz decorado de una fiesta ocasional de amigos que compartían nuevas canciones en una estimulante atmósfera de tentativa creativa constante (Shelton, 2010: 107).

La publicación de la revista Broadside se mantuvo como una influencia crucial en Dylan desde 1962 a 1964, llegando a encarnar no sólo un escaparate de sus canciones, sino un refugio tangible donde ampararse en otros músicos, comparar, experimentar y absorber las últimas influencias creativas y musicales. «Sis» Cunninghan, Friesen y Pete Seeger (impulsor último de la revista) eran aquellos amigos reconocidos que habían viajado por todo el país con Woody Guthrie, su gran amado escritor y compositor, y ahora les abrían las puertas de su casa y valoraban muy positivamente su incipiente creatividad musical.

\section{Ruptura con el crudo realismo follk: el proceso creativo de 'A Hard Rain's a-Gonna Fall'}

Según Sounes, el inquieto joven esbozó un borrador completo de A Hard Rain's A-Gonna Fall —prácticamente la canción tal y como se la conoce hoy día-, en una tarde de octubre, pero la mayoría de literatura dylanita imprescindible - Shelton, Scaduto, Margotin \& Guesdon, Heylin-, coinciden en trasladar esta noche a septiembre de 1962 - Clinton Heylin apunta que fue interpretada por primera vez en una noche del mismo mes de septiembre, en el bar Gaslight Café (Heylin, 1995: 32)—. Todo apunta a que la canción fue escrita por Dylan tecleando la maltrecha máquina de escribir Remington del artista y humorista Wavy Gravy en su 
apartamento, justo encima del bar Gaslight, en MacDougal Street. Como recuerda el cómico y poeta Gravy, que se encontraba presente mientras escribía: «brotó de él de la misma forma en que la pintura brotaba de Van Gogh» (Sounes, 2016: 159). La potencia poética de las canciones de Dylan comenzó a colorear un estándar del folk habituado a una literatura cruda y realista, un imaginario basado en las carreteras, los aserraderos y las penurias heredadas del baile popular sureño y el género fronterizo que cultivó el blues; estética e imaginario que habían revisado con creatividad prosindicalista Woody Guthrie, Pete Seeger, los Almanac Singer y en largo etc. en el Primer Folk Revival (1945-1955), todos ellos grandes referentes de Dylan (Malone, 1979). El mayor exponente mediático de los poetas beats, Allen Ginsberg, recuerda la primera vez que escuchó $A$ Hard Rain's a-Gonna Fall en una vieja grabación incluida en el documental de Martin Scorsese No Direction Home, y le otorga cierto romanticismo al acto de escucha que endulza y refuerza aquella imagen de poeta místico que comenzaba a envolver a Dylan:

When I got back from India, and got to the West Coast, there's a poet, Charlie Plymell - at a party in Bolinas - played me a record of this new young folk singer. And I heard "Hard Rain", I think. And wept. 'Cause it seemed that the torch had been passed to another generation. From earlier bohemian, or Beat illumination. And self-empowerment.

(No Direction Home, Scorsese, 2005)

Este comentario de Ginsberg no resulta extraño, a pesar de que la música folk y los recitales de la beat generation se solaparan con frecuencia durante la segunda mitad de la década de los cincuenta, sobre todo en el panorama cultural de San Francisco y New York. Con la música folk del Primer Folk Revival, los poetas beats - Peter Orlovsky, Ginsberg, Gregory Corso, Lawrence Ferlinguetti, Lenore Kandel, Anne Waldman, Elise Cowen, etc.- compartían la maravilla del viaje, el desdén por un modo de vida norteamericano basado en el consumismo y quizás la búsqueda interior de una honestidad íntima y verdadera expresada a través del arte. En el mejor de los casos, los poetas de la beat generation toleraban la unidimensionalidad de los estándares prosaicos de la música folk de los años treinta y los cuarenta, pero si existía un emblema musical de esta inconformista corriente poética, aquel era la trascendencia del sofisticado jazz — desde el bebop hasta el jazz experimental- (Wilentz, 2010: 63). Dylan mostraba en su material una síntesis mucho más acusada entre poesía y música popular. Si Blowing in the Wind, compuesta en abril del mismo año, se mostraba como el himno, la carta de presentación, A Hard Rain's a-Gonna Fall suponía la confirmación de aquella textura poética, romántica y genuina de las canciones de Dylan. El crítico y escritor Josh Dunson, en su artículo Birth of a Broadside, confirma esta insinuación con una comparación no tan precisa como aquella de Ginsberg: «Sigo pensando que él ha escrito algo realmente poético, como Blowing In the Wind y A Hard Rain's a-Gonna Fall, que te hace pensar directamente en Federico García Lorca ${ }^{1} »$ (Dunson, 1963: 10). Esta densidad «poética», sin duda, se encontraba íntimamente ligada al potente valor simbólico y a la depuración de su lenguaje, como veremos a continuación.

Parecía obvio, a nivel formal, que la canción de Dylan no se adecuaba a los estándares del folk por motivos mucho más evidentes. La segunda vez que Dylan interpretó $A$ Hard Rain ante una gran audiencia fue en el concierto de presentación de las Hootenannys ${ }^{2}$ organizadas por la revista Broadside, entre las butacas aterciopeladas de la Sala Carnegie Hall (New York), el 22 de septiembre de 1962. En el backstage, Pete Seeger arengaba a la nueva generación de jóvenes cantautores minutos antes de salir al escenario, de enfrentarlos al público: "Podéis cantar cada uno tres canciones, sólo tenéis diez minutos" —anuncia Seeger-. "¿Y qué se supone que tengo que hacer yo? Una de mis canciones dura diez minutos"» (Margotin \& Guesdon, 2015: 61). Las canciones tradicionales más populares del Segundo

\footnotetext{
Traducción del autor.

${ }^{2}$ La palabra original proviene de Irlanda y sirve para designar a un grupo de músicos que se unen para interpretar e improvisar canciones vinculadas al mundo del folk y sus variantes. El cantautor Woody Guthrie la había oído por primera vez en una Union Hall en el Paciffic Norhtwest en 1940 y consiguió integrarla en el mundo del folk norteamericano a principios de los cincuenta. En los sesenta, la palabra Hootenanny adquirió gran popularidad a la hora de designar a un grupo de músicos folk que tocaban juntos ocasionalmente $y$, generalmente, de manera improvisada.
} 
Folk Revival solían contener una duración de entre cuatro y cinco minutos salvo alguna excepción -Barbara Allen — Si bien la evidencia de la novedad en la estética de las canciones de Dylan se confirma con $A$ Hard Rain, su temática ha sido expuesta a todo tipo de interpretaciones sagaces y erróneas, procedimiento habitual por parte de la crítica especializada. Según una entrevista del periodista Nat Hentoff para las notas de la contraportada del disco The Freewheelin, Dylan deja entrever que la canción se gestó durante su pleno conocimiento de la crisis de los misiles de Cuba y su justificación en la amenaza de una guerra nuclear, lo que alejaría la teoría de que fuera escrita en septiembre, pese a todas las evidencias. También es cierto que la actitud pseudodadaísta - aún no tan acusada en estas fechas- se encuentra presente en todas las entrevistas de Dylan, haciendo imposible comprobar lo que conllevan de verdad o ficción. Lo que parecía cierto es que aquella tensa situación política de escalada previa entre Estados Unidos y Cuba en septiembre y, más tarde su explosión en octubre, supuso un impacto emocional y social en Dylan, como no podía ser de otra manera. En una de las cartas enviadas a Suze, su compañera sentimental que por aquel entonces se encontraba en Italia, Dylan atrapa el angustioso ambiente de este periodo:

Me siento en Le Figaro todas las noches esperando que se acabe
el mundo (la primera noche que habla Kennedy y los barcos
Rusos se están acercando a Cuba). Te juro por Dios que pensé
que se había acabado. No es que me importe una mierda (eso
es mentira, creo), pero fue interesante esperar a que cayeran
las bombas y te mataran -y realmente me pareció que lo ha-
cían-. Si el mundo se acabara esta noche, todo lo que me gus-
taría sería estar contigo. Y eso es imposible porque estás muy
lejos. Y por eso pareció tan desesperanzador.

(Rotolo, 2008: 195)

Dylan se veía obligado a componer una canción que reflejara toda su experiencia acumulada: «Cada verso de ella [la canción] es en realidad el inicio de una canción entera. Pero cuando la compuse, pensé que no viviría lo bastante como para escribir todas esas canciones,

3 Traducción del autor. así que puse todo lo que pude en una» (Paul Williams, 2004: 71). En la imprescindible biografía del periodista italiano Scaduto, Dylan aclara algo que no debería aclarar con respecto a $A$ Hard Rain; esto es, que la canción pretende comunicar justamente aquello que las palabras de la canción pretende comunicar [...]: «no es una lluvia atómica. Sin embargo, muchas personas piensan eso» (Scaduto, 1972: 127).

\section{Análisis poético de 'A Hard Rain's a-Gonnarall'}

En cuanto a su estética, merece la pena detenerse en la cantidad de referencias y recursos literarios que Dylan fue asimilando en sus dos años y medio en New York hasta llegar a componer un texto como $A$ Hard Rain's aGonna Fall. Observamos una estructura poco ortodoxa, más similar a un poema de Verlaine que a una canción folk. La balada despliega un elenco de imágenes apocalípticas de lienzo expresionista, un texto profético bañado de inquietantes símbolos desoladores y metáforas siniestras. A continuación, nos acercaremos a un análisis de la estructura global del texto, para luego concretar y desgranar el uso de su lenguaje y los recursos estilísticos que emplea $A$ Hard Rain's a-Gonna Fall.

\subsection{Carácter antifonal: Salut Au Monde! de Walt Whitman y la balada de Lord Randal}

Durante la canción, encontramos una estructura de carácter antifonal (del griego la voz que responde). Se observa una voz poética que sugiere un carácter paternal o maternal condenada a la pregunta y a una voz más joven que intenta responder disponiendo una serie de imágenes y situaciones abrumadoras — tanto en número como en expresividad-: un desasosegado diálogo entre dos voces poéticas. Si algo ha distinguido a Dylan como creador, quizá sea la capacidad de modular la materia prima artística y concederle una re-significación 
y actualización polisémica y sincrónica. La estructura poética y musical de A Hard Rain's a-Gonna Fall bebe fundamentalmente de dos textos previos: de la balada popular anglo-escocesa Lord Randal, a nivel melódico y de estructura, y del poema Salut Au Monde! de Walt Whitman, a nivel expresivo. De la balada tradicional de Lord Randal, Dylan toma la estructura antifonal y la melodía propia de la balada clásica:

\begin{abstract}
«Where have you been, Randal my son?
Where have you been, my handsome young one?» «I've been to the wildwood, mother, make my bed soon For I'm sick to my heart and I want to lie down.» «Who did you meet there, Randal my son? Who did you meet there, my handsome young one?» «I met with my true love, mother, make my bed soon For I'm sick to my heart and I want to lie down.» «I fear you are poisoned, Randal my son! ${ }^{4}$
\end{abstract}

La balada de Lord Randal narra la historia de un joven lord escocés que regresa a casa tras un largo viaje. Su madre le interroga sobre qué ha sido de su vida durante su viaje haciendo uso de una estructura muy habitual de las baladas irlandesas basada en la repetición. Al final se descubre el motivo del fatigado cansancio de Lord Randal durante toda la canción: su amada le ha envenenado. Como afirmaba el propio Dylan en una entrevista de 1962:

La lluvia atroz que va a caer se encuentra ahí, en el último verso donde digo «las perlas de veneno están flotando en sus aguas». Me refiero a todas las mentiras que les cuentan a la gente en la radio y en los periódicos, tratando de volverla loca, todas las mentiras que considero veneno. ${ }^{5}$

(Scaduto, 1972: 127)

La estructura de Lord Randal se eufemiza en $A$ Hard Rain, como se observa en el ejemplo:

\footnotetext{
${ }^{4}$ ¿Dónde has estado Lord Randal, hijo mío?/ ¿Dónde has estado, Lord Randal, jovencito?/He estado en los bosques salvajes, madre hazme la cama pronto/ Porque tengo el corazón enfermo y quiero echarme/ ¿A quién conociste, Lord Randal, hijo mío? ¿ ¿A quién conociste, Lord Randal, jovencito?/ Conocí a mi amor verdadero, madre hazme la cama pronto/ Porque estoy enfermo del corazón y quiero echarme/ Me temo que te han envenenado, ¡Lord Randal, hijo mío!

${ }^{5}$ Traducción del autor.
}

Oh, where have you been, my blue-eyed son?

Oh, where have you been, my darling young one?

I've stumbled on the side of twelve misty mountains

I've walked and I've crawled on six crooked highways

I've stepped in the middle of seven sad forests

I've been out in front of a dozen dead oceans

I've been ten thousand miles in the mouth of a graveyard

And it's a hard, and it's a hard, it's a hard, and it's a hard

And it's a hard rain's a-gonna fall

Sin embargo, a nivel expresivo y formal, $A$ Hard Rain'rompe la estructura de cuatro versos por estrofa y parece que la voz poética quiera expresar todo aquello que haya ahoyado en esta tierra: —Vi, Oí, Conocí, Hallé-. En cuanto a la expresividad en el lenguaje, parece que existen deudas evidentes con Salut Au Monde! del poeta Walt Whitman, no tanto en el lenguaje, sino en la acumulación de versos e imágenes apegados a los sentidos:

\section{O TAKE my hand, Walt Whitman}

Such gliding wonders! such sights and sounds!

Such join'dunended links, each hook'd to the next!

Each answering all-each sharing the earth with all.

What do you hear, Walt Whitman?

I hear the Coptic refrain, toward sundown, pensively falling on the breast of the black venerable vast mother, the Nile;

I hear the workman singing, and the farmer's wife singing;

I hear in the distance the sounds of children, and of animals early in the day;

I hear quick rifle-cracks from the riflemen of East Tennessee and Kentucky, hunting on hills [...]

What do you see, Walt Whitman?

Who are they you salute, and that one after another salute you?

I see a great round wonder rolling through the air;

I see diminute farms, hamlets, ruins, grave-yards, jails, factories, palaces, hovels, huts of barbarians, tents of nomads, upon the surface;

I see the shaded part on one side, where the sleepers are sleeping - and the sun-lit part on the other side, I see the curious silent change of the light and shade,

I see distant lands, as real and near to the inhabitants of them, as my land is to me

(Whitman, 2013: 173) 
Para mayor comodidad, y con el fin de visualizar mejor la canción, reproducimos las estrofas de manera íntegra y con los versos debidamente numerados:

Oh, where have you been, my blue-eyed son?

$\mathrm{Oh}$, where have you been, my darling young one?

I've stumbled on the side of twelve misty mountains

I've walked and I've crawled on six crooked highways

I've stepped in the middle of seven sad forests

I've been out in front of a dozen dead oceans

I've been ten thousand miles in the mouth of a graveyard

And it's a hard, and it's a hard, it's a hard, and it's a hard

And it's a hard rain's a-gonna fall

Oh, what did you see, my blue-eyed son?

Oh, what did you see, my darling young one?

I saw a newborn baby with wild wolves all around it

I saw a highway of diamonds with nobody on it

I saw a black branch with blood that kept drippin'

I saw a room full of men with their hammers a-bleedin'

I saw a white ladder all covered with water

I saw ten thousand talkers whose tongues were all broken

I saw guns and sharp swords in the hands of young children

And it's a hard, and it's a hard, it's a hard, it's a hard

And it's a hard rain's a-gonna fall

And what did you hear, my blue-eyed son?

And what did you hear, my darling young one?

I heard the sound of a thunder, it roared out a warnin'

Heard the roar of a wave that could drown the whole world

Heard one hundred drummers whose hands were a-blazin'

Heard ten thousand whisperin' and nobody listenin'

Heard one person starve, I heard many people laughin'

Heard the song of a poet who died in the gutter

Heard the sound of a clown who cried in the alley

And it's a hard, and it's a hard, it's a hard, it's a hard

And it's a hard rain's a-gonna fall

Oh, who did you meet, my blue-eyed son?

Who did you meet, my darling young one?

I met a young child beside a dead pony

I met a white man who walked a black dog

I met a young woman whose body was burning

I met a young girl, she gave me a rainbow

I met one man who was wounded in love

I met another man who was wounded with hatred

And it's a hard, it's a hard, it's a hard, it's a hard

It's a hard rain's a-gonna fall
Oh, what'll you do now, my blue-eyed son?

Oh, what'll you do now, my darling young one?

I'm a-goin' back out 'fore the rain starts a-fallin'

I'll walk to the depths of the deepest black forest

Where the people are many and their hands are all empty

Where the pellets of poison are flooding their waters

Where the home in the valley meets the damp dirty prison

Where the executioner's face is always well hidden

Where hunger is ugly, where souls are forgotten

Where black is the color, where none is the number

And I'll tell it and think it and speak it and breathe it

And reflect it from the mountain so all souls can see it

Then I'll stand on the ocean until I start sinkin'

But I'll know my song well before I start singin'

And it's a hard, it's a hard, it's a hard, it's a hard

It's a hard rain's a-gonna fall

\subsection{Estructura global del texto: métrica y rima}

La estructura global de $A$ Hard Rain se despliega de la siguiente manera: Pareado-5versos/Pareado-7 versos/ Pareado-7 versos/Pareado-6 versos/Pareado-12 versos. Cuando el lector se enfrenta a un texto, la disposición espacial fijada en el papel conduce al lector ante la posibilidad de conocer el final del propio texto, sin embargo en la canción todo es dinamismo y fluidez, y Dylan es consciente de esta diferencia. Para entronar su conclusión, dobla la cantidad de versos en la última estrofa, lo que crea una tensión entre el espectador y los versos que escupe la canción y que alcanza su clímax con la lluvia atroz. Así pues, nos disponemos a desgranar las dos voces poéticas que preñan la canción de significado:

\subsubsection{Primera vozpoética: el eco materno/paterno}

Los dos versos que abren cada estrofa — aquellos que evocan la irremediable pregunta - vuelcan una repetición o anáfora que enmarcan el pasado de la voz poética a la cual se pregunta, apuntando algunos sentidos — vista, oído- y cerrando con una conjura hacia el futuro:

What'll you do now my blue-eyed son?

Oh, what'll you do now, my darling young one? 
Se trata de un pareado - dos versos con rima perfecta- que Dylan diferencia con tres recursos formales y sonoros:

1) Una diferenciación musical/conceptual. Dylan comienza $A$ Hard Rain con una frase musical inicial en MI MAYOR — «Where have you been my blue-eyed son?/ Where have you been my darling young one?)- muy distinta al recurso musical que acompaña a la voz poética del joven, con arreglos en acordes mayores. Ambas voces se encuentran separadas por un SI MAYOR que marca la diferencia entre las dos voces poéticas.

2) Con una rima perfecta entre «son» y «one».

3) Con las terminaciones de los versos en sílaba tónica.

\subsubsection{Segunda vozpoética: el joven}

En cuanto a la respuesta poética, fijémonos en la cadencia de la primera frase. Toda la canción muestra una tendencia al yámbico. El yambo es un pie de métrica muy común en la poesía inglesa que comprende una sílaba átona y otra tónica, encadenándose un ritmo zigzagueante en la pronunciación. El idioma inglés tiende naturalmente al ritmo yámbico como el español al endecasílabo. La canción parece como mecerse en sí misma gracias a este recurso métrico que Dylan emplea prácticamente en toda la canción. Ejemplos: «I saw a white ladder all covered with water/I heard ten thousand whisperin' and nobody listenin». Los versos se desvelan como de ida y vuelta del yámbico, llegando al culmen de la frase melódica a mitad de verso: "I've stumble on the side of Twelve misty mountains».

Con respecto a las respuestas que articula la segunda voz poética, Dylan concede forma átona a las terminaciones de cada uno de los versos que, unidos a este vaivén con tendencia al yámbico, trepan en un dinamismo huidizo, sordo y esquivo a las terminaciones en rimas y se mantiene en una cadencia percutiva en sílaba átona que forma la terminación «ing». En algunos versos, Dylan recurre a la orfebrería poética, como es el caso del verso 7 , donde aprovecha el final de verso para sincopar el primer estribillo «graveyard/it's a hard». De nuevo en el verso 40: «Hatred», que como comenta el crítico literario Christopher Ricks (2016: 354), sobreviene tra- gado por «hard». Hacia el final, como coronación, Dylan marca el final de la canción con una rima:

I start sinking

I start singing

En el nivel fónico, además de estos recursos rítmicos, Dylan aligera y embellece la canción con el uso de aliteraciones, repeticiones de sonidos o fonemas en un verso con finalidad expresiva — «dozen, dead oceans》(verso 6)/ «thousand miles in the mouth» (verso 7)/ «with wild wolves» (verso 12)-, y con algunas rimas internas: «ten thousand talkers whose tongues were all brokenı (verso 17).

\subsubsection{Referencias literarias y estilísticas}

Así mismo, la canción parecía referenciar a algunos textos emblemáticos de la literatura y de la antigua balada popular. El libro Letras nombra a la balada inglesa medieval de Nottamund Town donde aparece el verso «ten thousand got drown that never was borns, eufemizado en la canción de Dylan por «Ive ten thousand miles in the mouth of a graveyard», señalando al «no nacido»con el cementerio. Como esclarece el libro Letras, la canción también puede hacer referencia a Cad Goddeu - la batalla de los árboles-, un antiguo poema celta que Dylan pudo haber conocido gracias a la versión introducida por el poeta inglés Robert Graves en el libro La diosa Blanca. El libro de Robert Graves es citado con frecuencias en los análisis de la canción - tanto en Ricks, como en las notas de Alessandro en Letras-.

La frase «I saw a black branch with blood that keep dripling»recuerda irremediablemente a toda una tendencia mitológica que aúna la carne y sangre humanas con motivos vegetales y telúricos; desde la tragedia de Apolo y Dafne hasta Petrarca y el episodio de Pierre de la Vigne de la Divina Comedia de Dante en el Infierno XIII, 43-44 — «i della scheggia rotta usciva insieme/ parole e sangue»—. Según el mitólogo Cassirer, la descendencia y transformación del hombre de una determinada variedad de planta, así como la idea de la metamorfosis entre plantas y animales, «constituyen un motivo permanente del mito y de las leyendas mitológicas» (Cassirer, 1998: 234). Atendiendo al Edda (el libro más antiguo de la mi- 
tología nórdica), la pareja humana primordial fue creada por Odín a partir de dos árboles, Askr y Embla, que se encontraban sobre la playa del océano, así como numerosos mitos suñíes, africanos y australianos que evocan la relación entre el génesis humano con el reino vegetal.

En el apéndice del volumen Bob Dylan: Letras, traducido por Miguel Izquierdo, Alessandro Carreras apunta que $A$ Hard Rain también parece aludir al poema El spleen de Las flores del mal de Baudelaire: «El alma de un viejo poeta vaga por el desagüe»: «Heard de son of a poet who die in the gutter». El libro traducido por Miguel Izquierdo también identifica la estructura de $A$ Hard Rain - los versos que comienzan en «Vi, Oí y Hallé»_ con el poema El Barco Embriagado de Arthur Rimbaud (2001: 162) — poeta con el que se ha relacionado a Dylan hasta la saciedad_-, pero su expresividad y repetición de los sentidos en los versos se asemeja mucho más al ya citado poema Salut Au Monde de Walt Whitman — ¿What do you hear, Whalt Whitman?/I hear the workman singing and the farmer's wife singing»-, con la apertura del primer verso en interrogativa, y que curiosamente se muestra desaparecido en el volumen de Letras. Quizás le influyeran tanto Whitman (en el uso expresivo de la repetición de los sentidos para organizar el texto) como Rimbaud (por su oscuro simbolismo). Si nos parece pertinente resaltar que muchos versos de la estrofa de la canción comparten estructura y métrica con la poetizidad de Ginsberg en Howl: «Moloch whose eyes are a thousand blind windows» (2001: 163). Coincidimos en que el libro de Letras, pese a traer a coalición realidades muy posibles de la canción, en contadas ocasiones hace uso de su hermenéutica referencial con cierta ligereza, atribuyéndole unas licencias al texto que a veces alejan a la canción del enriquecimiento en su posible significación.

Las referencias aquí citadas y el lenguaje simbolista parecen indicar que el posicionamiento creativo de Dylan se alejaba del realismo del «objeto»y del «exterior»propio del Primer Folk Revival y se interesaba por el «interion»romántico (mythos). Dylan siempre ha sido pródigo en imágenes y en recursos sonoros percutivos. En el Primer Folk Revival, lo más lejos que pa- recía entregarse el lenguaje era a la alegoría. La alegoría se encuentra apegada al concepto abstracto, al (logos), mientras que Dylan supuso de los primeros cantautores aclamados por el stablishment del Segundo Folk Revival que parecía interesado decididamente por el lenguaje de símbolo, un territorio en teoría más abierto a la experimentación, al inconsciente y a lo onírico. Para Corbin, el símbolo muestra su independencia de las realidades inmóviles que sugiere la alegoría:

El símbolo propone un plan de conciencia que no es el de la evidencia racional; es la «cifra»de un misterio, el único medio expresivo que no puede ser aprehendido de otra forma, nunca es explicado de una vez para siempre, sino que ha de ser descifrado continuamente, de la misma manera que una partitura musical nunca es cifrada para siempre, sino que sugiere una interpretación siempre nueva.

(Corbin, 1993: 26)

Si atendemos a esta definición de Corbyn, diremos que el símbolo es «indefinible»y no trabaja tanto con codificaciones abstractas, sino con evocaciones emocionales y significados siempre revisables, ya que intentan encerrar este «misterio», estas «relaciones emocionales complejas». Como decía Dylan, «la canción quiere decir lo que quiere decin»; no hay nada que se pueda expresar de otra manera más que con el símbolo. El verdadero símbolo poético en sí sólo puede ser intuido. Según Shelton, una fuente muy cercana a Dylan, el musicólogo Harry Webber, asegura que desde sus años de estudiante en Minesota (Dinkytown), Dylan siempre llevaba bajo el brazo el libro Antología de los Poetas Simbolistas Franceses (Shelton, 2010: 57) —una panorámica desde Nerval hasta Apollinaire, según divisó el propio Van Ronk ya en su piso de New York (Scaduto, 1972) —. Por otra parte, otras influencias más libres en el lenguaje parecen aderezar el texto: Dylan ya conocía la literatura de Jack Kerouac _-On the Road-y Allen Ginsberg - Kaddish, Howl_ cuando llegó a New York y por el tiempo en que escribió $A$ Hard Rain.

\subsection{Estribillo}

En el estribillo, que la canción sugiere que es pronunciado por la segunda voz poética (joven), se observa 
una epifora o la repetición de una o varias palabras al final de una frase o verso, en este caso «Hard». Esta repetición crea en el espectador una doble resonancia: el anhelo inminente y la intensidad de la misma «lluvia». Es un torrente secuencial que aumenta en intensidad dramática durante la interpretación elevando la intensidad - de nuevo una diferencia con el texto escrito, que sólo puede expresar esta intensidad por la grafía $« !) —$. El agua es principio y final del ser humano, el diluvio bíblico y la premonición de una actualización apocalíptica que purifique al mundo.

\section{Conclusiones}

Partiendo de una base estructural y melódica puramente tradicional (la balada de Lord Randal), el oscuro lenguaje de $A$ Hard Rain's a-Gonna Fall se apoya en una tradición poética de una gran carga simbólica que trabajó primeramente la poesía francesa, y cuya búsqueda oscura de lo inasible venía a remarcar la crisis espiritual y humana del Fin de Siglo XIX —el nihilismo nietzscheano y la crisis de la razón en Kant-, unos postulados estéticos que comenzaban a esbozar las dinámicas sociales propias de los medios de comunicación de masas y la réplica (Warhol). El mythos (misticismo) de A Hard Rain's a Gonna Fall se muestra patente en la acepción de un lenguaje que cancela todo realismo o esbozo de representación fidedigna de la realidad (logos), toda realidad que cincelaban y esclarecían las antiguas canciones leftartist de corte sindicalista del Primer Folk Revival, donde Pete Seeger, Lee Hays y Woody Guthrie cantaban desde una ideología clara y definida y animaban a las clases desfavorecidas a la soportabilidad del trabajo con acordes y letras imbuidas del realismo crudo expresadas en el lenguaje del pueblo. En este sentido, la pérdida de las grandes ideologías, de lo asible, deviene en búsqueda de la trascendencia por una superación y depuración del lenguaje en la incipiente obra de Dylan. Con el tiempo, esta tesis sobre la crisis de nuestro tiempo y la obra de Dylan parece comprobarse: los próximos discos del bardo de Duluth incluirán figuras y recursos más propios de las vanguardias europeas — surrealismo, dadaísmo, cubis- mo- - un estilo aún más acentuado en la fragmentación y los territorios líquidos que marcan la pauta neurótica, sincrónica y fascinante de nuestro tiempo creativo.

\section{Bibliografía}

C. Malone, Bill y Stricklin, David (2003), Southern Music/ American Music. Kentucky: University Press of Kentucky. Cassirer, Ernst (1998), Filosofía de las formas simbólicas II, México: Fondo de Cultura Económica.

Dunson, Josh (1963), «Birth of a Broadside», en Broadside, 20, New York.

Feria VÁzquez, Miguel Ángel (2015), «Parnasianismo y simbolismo en la encrucijada de la modernidad: hacia una revisión general de sus vínculos», en Thélème. Revista Complutense de Estudios Franceses, vol. 30, n. ${ }^{\circ}$ 2, págs. 203-221. Recuperado de: file:///C:/Users/Jesus/Downloads/47774-Texto $\% 20$ del $\% 20$ art $\%$ C3\%ADculo-91457-1-10-20151102.pdf.

Heylin, Clinton (1996), A Life in Stolen Moments. New York: Schirmer Books.

IzQuierdo, Miguel, Moreno, José y CARrera, Alessandro (2011), Bob Dylan. Letras, 1962-2001. Barcelona: Global Rhythm.

Margotin, Philippe y Guesdon, Jean-Michel (2015), Bob Dylan. Todas sus canciones. La historia detrás de sus 492 temas, Barcelona: Art Blume.

Ricks, Christopher (2016), Dylan poeta. Visiones del pecado, Madrid: Los libros de la Catarata.

Rotolo, Suze (2008), A Freewheelin' Time, New York: Broadway Books.

Scaduto, Antony (1972), Bob Dylan. An intimate biography, Londres: W. H. Allen.

SCORSESE, Martin (2005), No Direction Home. Paramount Pictures. SHELTON, Robert (2011), No Direction Home. The Life \& Music of Bob Dylan, Londres: OmnibusPress.

SounEs, Howard (2016), Bob Dylan. La biografía, Barcelona: Reservoir Books

Whitman, Walt (2013), Leaves of Grass. The Electronic Classic Series. Recuperado de: https://edisciplinas.usp.br/ pluginfile.php/3985648/mod_resource/content/1/ LEAVES\%20OF\%20GRASS.pdf.

WiLENTZ, Sean (2011), Bob Dylan in America, Londres: Vintage. Williams, Paul (2004), Bob Dylan. Años de juventud, Barcelona: Ediciones Robinbook. 

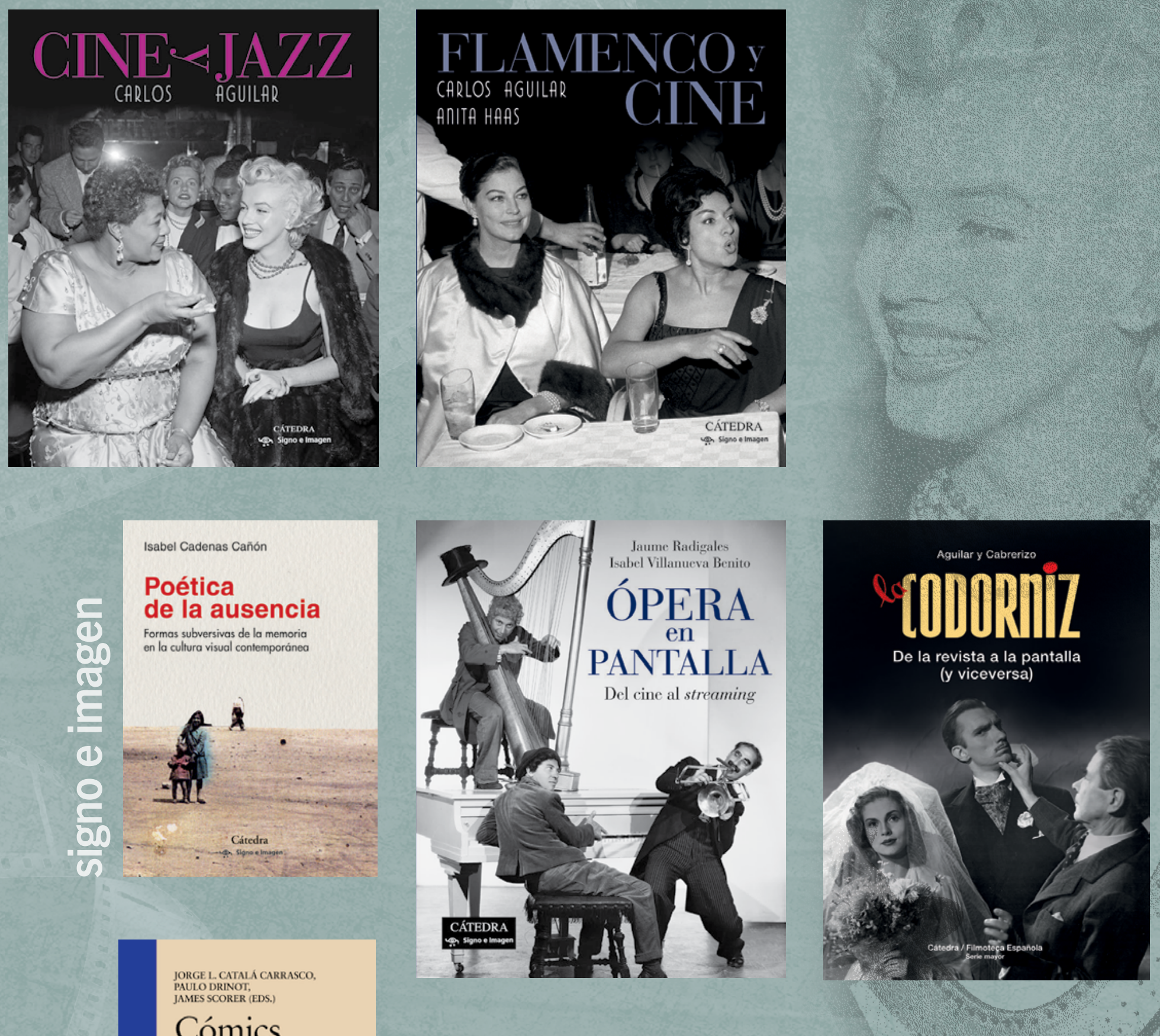

JORGE L.CATALA C
PAULO DRINOT,
JAMES SCORER

Cómics y memoria en América Latina
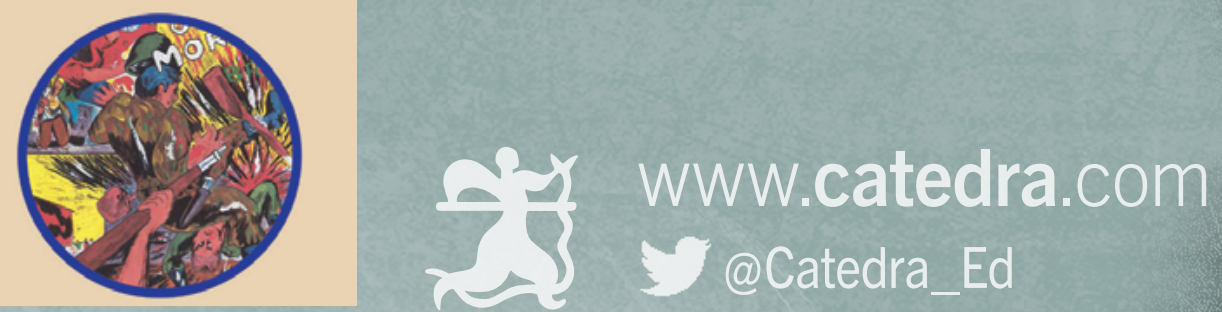